\title{
Actores y acciones: el liberalismo político en Michoacán (1851-1861)
}

Actors and Actions: the Political Liberalism in Michoacan (1851-1861)

\section{Alejandro Mercado Villalobos}

División de Ciencias Sociales y Humanidades

Universidad de Guanajuato, Campus León

alejandro.mercado@ugto.mx

Recibido: 7 de febrero de 2018 - Aprobado: 4 de abril de 2018

Cómo citar este artículo: Alejandro Mercado Villalobos, "Actores y acciones: el liberalismo político en Michoacán (1851-1861)", en Legajos. Boletín del Archivo General de la Nación, núm. 16 (mayo-agosto 2018), pp. 35-66.

\section{Resumen}

El objetivo de este trabajo es el examen del proceso de imposición del proyecto liberal en Michoacán. En él se buscar mostrar la manera en que, desde los actores y sus acciones, en la entidad se siguió la política de transformación nacional encabezada por Benito Juárez y el grupo de los liberales. Se aborda la cuestión a partir de tres momentos. El primero inicia con la exploración de un proyecto de reforma a las obvenciones parroquiales, presentado en 1851. Se continúa con el estudio de las intenciones por erigir un marco legislativo liberal luego de la Revolución de Ayutla. Para terminar con el análisis de la época del liberalismo radical, encabezado en Michoacán, por el general Epitacio Huerta.

Palabras clave: liberalismo, política, igualdad, libertad, democracia

\section{Abstract}

I propose with this work the analysis to the process of imposition of the liberal project in Michoacán. My intention is show how the actors and their actions, followed the liberal project in favor to the national politic transformation, that headed by Benito Juarez. I analyze the sitvation in three moments. The first begins in 1851, with the reform project of the parish benefits. Next, I analyze the intentions for establishment in Michoacán a liberal legal framework, after the Ayutla Revolution. I finish with the study of the radical liberalism, headed in Michoacán for the general Epitacio Huerta.
Keywords: liberalism, politics, equality, freedom, democracy 


\section{Introducción}

La Reforma liberal en México se formalizó en agosto de 1855, con la promulgación de la Ley Juárez, que en esencia establecía la igualdad ante la ley y el inicio en el país, de una profunda transformación política de "espíritu liberal". Además, como alegó con sólidos argumentos el entonces joven abogado jalisciense Ignacio Vallarta, en 1856, desde el proyecto liberal se intentó constituir al país teniendo la democracia como sistema, y los axiomas libertad e igualdad como ejes elementales de construcción nacional. ${ }^{2}$

La amplia historiografía al respecto indica un complejo entramado político y con múltiples aristas, en tanto a la aplicación del modelo liberal en México, en especial por la interpretación que de la doctrina hicieron sus impulsores, no solo en la capital del país sino en provincia. Precisamente, la visión que deriva de estudios regionales del movimiento político y económico que significó la Reforma liberal, hace pertinente analizar el proceso en cuestión, a partir de un escrutinio preciso y concreto de casos particulares, sobre todo de los espacios de lucha por el poder, distinguidos desde la historiografía como emblemáticos del liberalismo mexicano.

Trabajos como el de Carmen Blázquez sobre el Veracruz liberal, remiten a afirmar que el debate político en torno al tema no fue exclusivo de la capital del país, y que es posible, desde el análisis de casos regionales, ofrecer una perspectiva amplia y precisa del proceso que significó la Reforma liberal en México. ${ }^{3}$ Son varios los ejemplos

${ }^{1}$ Véase Villegas Revueltas, "Santannismo", pp. 23-24.

2 Abogado, nació en 1830. Ocupó diversos cargos públicos. Fue gobernador de Jalisco, magistrado y presidente de la Suprema Corte de Justicia. Destacado escritor en temas de derecho, en especial del juicio de amparo y de las garantías individuales. En 1856 se encargó del discurso que en Guadalajara se ofreció, en el marco de las festividades por el aniversario de la Independencia de México en tiempos del gobierno estatal de Santos Degollado, oportunidad desde donde expresó su idea del liberalismo. Galván Rivera, Derecho procesal, p. 178.

${ }^{3}$ Blázquez Domínguez, Veracruz liberal, 269 pp. 
en este sentido. Silvestre Revueltas estudió el caso de Puebla durante la época de Santa Anna y el preludio de la Constitución de 1857. ${ }^{4}$ En otro análisis similar, Víctor Núñez examinó la elite poblana en tanto a los actores intelectuales que encauzaron la Reforma en dicha entidad. ${ }^{5}$ De éstos y otros trabajos, como el de Gustavo Herón Pérez sobre Nuevo León, ${ }^{6}$ y el de Luis Alberto Arrioja Díaz sobre Oaxaca, se deduce la importancia del estudio del proceso a partir de las perspectivas regionales, ya que es posible percibir desde dichos espacios de análisis, temas inherentes al proyecto liberal, entre ellos el importante papel de los actores políticos y las acciones emprendidas en la imposición de sus objetivos, y los ritmos en que ocurrió el proceso que culminó en la imposición de la Reforma en México, que cambió radicalmente la vida política nacional.

En este sentido, me interesa encargarme del caso michoacano debido a que realicé, a colación de mi tesis de maestría en historia, una investigación titulada "El liberalismo político en Michoacán, 1851-1861". En la indagatoria - de la cual deriva evidentemente el presente trabajo--, identifiqué un entramado político distinguible en tres momentos. El primero aparece definido por la propuesta que, en 1851, impulsó Melchor Ocampo en torno al tema de las obvenciones parroquiales; la cuestión ocasionó las primeras fricciones entre los actores de la política local y la Iglesia michoacana. El segundo se distingue en los intentos por reconstruir el aparato de Estado luego de la Revolución de Ayutla, determinado por la intención, desde el Legislativo estatal, por impulsar un marco constitucional desde la doctrina liberal. El tercero, denominado el liberalismo radical, se trata del periodo de gobierno del general Epitacio Huerta, quien intentó, con acciones concretas, llevar a la práctica en Michoacán las Leyes de

\footnotetext{
${ }^{4}$ Villegas Revueltas, Santannismo, pp. 13-52.

${ }^{5}$ Núñez García, Los orígenes del liberalismo, pp. 43-87.

${ }^{6}$ Herón Pérez, El caso del liberalismo vidaurrista, pp. 95-115.

${ }^{7}$ Arrioja Díaz Viruell, Pueblos, reformas, pp. 487-531.
} 
Reforma. Se trató de una época sumamente complicada por la polarización de la sociedad, y los conflictos derivados del debate nacional en torno al proyecto liberal nacional.

En suma, el trabajo que a continuación se expone es un examen de los actores políticos y sus acciones, en el complicado proceso de construcción del Estado liberal en Michoacán. ${ }^{8}$

\section{E1 momento liberal}

El 11 de marzo de 1851, en el pleno del Congreso de Michoacán, el diputado Ignacio Cuevas presentó un proyecto de reforma sobre el tema de las obvenciones parroquiales. ${ }^{9}$ Se suscitó entonces un debate entre Melchor Ocampo - entonces senador de la República y de quien se sabe fue el impulsor del proyecto- y un personaje que se autonombró "un cura de Michoacán", de quien se deduce fue el propio Clemente de Jesús Munguía. ${ }^{10}$ La polémica, que tuvo alcance nacional porque se tocó el tema de la separación entre el Estado y la Iglesia, en relación con sus ámbitos de competencia y del que derivó el complejo asunto de la tolerancia de cultos, significó un debate abierto entre un liberal confeso, Ocampo, quien se perfilaba ya como el líder de los liberales michoacanos, y un representante de la Iglesia mexicana,

${ }^{8}$ Para el caso michoacano, en el libro Los obispados de México frente a la reforma liberal Juvenal Jaramillo publicó un estudio al respecto. El trabajo es preciso, completo y sumamente cuidadoso del desarrollo político derivado de la Reforma y en específico, de las afectaciones a la Iglesia y sus fueros y privilegios. Véase Olveda, Los obispados, 397 pp. La diferencia con este trabajo es que el texto de Jaramillo mira la Reforma desde la óptica exclusiva de los miembros del Cabildo Eclesiástico, en tanto que este examen reviste los actores de la política y sus acciones.

${ }^{9}$ Los servicios religiosos estaban regidos en 1851 por una ordenanza dictada en 1731 . El documento puede consultarse en Arreola Cortés, Obras Completas, pp. 19-24.

${ }^{10}$ Siguiendo a Raúl Arreola Cortés, uno de los biógrafos más importantes de Ocampo y quien escribió una de las más completas reseñas de la polémica, sostiene que Munguía habría estado detrás de la polémica sobre el proyecto de reforma a las obvenciones parroquiales. Véase Obras completas, tomo II. 
Munguía, quien sería uno de sus defensores más importantes de cara a la Reforma liberal decimonónica. ${ }^{11}$

El momento fue significativo por la efervescencia política causada en enero de 1851, cuando Munguía se negó a jurar la Constitución mexicana como requisito para su posesión como obispo de Michoacán, alegando que el texto del juramento ponía en peligro "...los derechos y libertades de la Iglesia". ${ }^{12} \mathrm{El}$ asunto detonó en acciones concretas, y una fue, precisamente, la presentación del proyecto sobre las obvenciones parroquiales en el Congreso local.

Luego de una discusión previa, los legisladores michoacanos llevaron el asunto al pleno en la sesión del 8 de agosto de 1851. El debate suscitado entonces es significativo para el pensamiento liberal michoacano. Por una parte, se discutió que, en efecto, era necesaria una reforma en el tema en cuestión pues la Iglesia aún tasaba a los feligreses por castas, una categoría extinta desde los albores de la República, además, se sabía de abusos por parte de curas, sobre todo a los sectores pobres.

Aquella oportunidad permitió discutir el hecho de que aún existían en el estado de Michoacán, oligarquías que impedían que se observara la igualdad como principio jurídico. Al respecto, un diputado expresó que el gobierno debía garantizar, por todos los medios posibles, que las leyes se aplicaran con todo el peso suficiente para garantizar, además, la independencia y la libertad, ya que esto daría por consecuencia

${ }^{11}$ La polémica se extendió a varios escritos: cinco por parte de Ocampo, y tres por parte de Munguía. Arreola Cortés, Obras completas, tomo II. La historiografia implica a Munguía, en efecto, como uno de los eclesiásticos que mayormente defendieron a la Iglesia mexicana. Consúltese al respecto la obra de Pablo Mijangos y González, Las vías de lo legitimo, pp. 151-221; Clemente de Jesús Munguía, pp. 167-198; The lawyer of the Church, 355 pp.

${ }^{12}$ Véase al respecto a Ornelas, El obispo de Michoacán, pp. 253-271; Mijangos, Las vías de lo legítimo, pp. 201-202; Mijangos, Clemente de Jesús Munguía, pp. 184-186. El asunto, además, como ha estudiado Sergio Rosas, fue de trascendencia nacional, incitando el debate de los límites del poder el Estado y la Iglesia y el papel de esta con la sociedad. Rosas, ¿Libertad de conciencia?, pp. 71-101. 
una sociedad más justa. ${ }^{13}$ Esto coincide con el fin de los gobiernos que postulaba Jeremy Bentham y el utilitarismo - pensamiento ampliamente difundido en México como ha comprobado Charles Hale- ${ }^{14}$ en relación con la felicidad del individuo como meta de Estado.

El caso aquí es que los legisladores michoacanos buscaron un arreglo frontal con la Iglesia, intentando formalizar una reforma, primero, con el tema citado de las obvenciones parroquiales, para lo cual se propusieron culminar el asunto de forma inmediata. ${ }^{15}$ Tal decisión tuvo origen en el hecho de que, desde que se supo del proyecto en el interior del territorio, varios ayuntamientos michoacanos externaron su apoyo al Congreso, incitando incluso, a implementar medidas reformistas en ese y otros temas, en el ámbito local. ${ }^{16}$

Las autoridades de la Iglesia en Michoacán evadieron la discusión propuesta por el Congreso. Incluso, ni siquiera en las sesiones de cabildo eclesiástico se abordó el asunto, quizá a sabiendas de que al dar cause a un debate, al respecto podría ser la apertura hacía otra reforma mayor. En una revisión de las actas del Cabildo Eclesiástico, no aparece registro alguno que permita asumir, a priori, que la propuesta de reforma de obvenciones por parte del Congreso michoacano haya sido apuntada en las discusiones, de lo que se deduce que, por parte de la Iglesia, ni siquiera se pensó en la posibilidad de reformar algo que consideraba suyo y en el ámbito de competencia desde la época virreinal. ${ }^{17}$

\footnotetext{
${ }^{13}$ Congreso del estado de Michoacán, sesión del 8 de agosto de 1851, AHCEM, actas públicas.

${ }^{14}$ Hale, El liberalismo, capítulo v.

${ }^{15}$ En la sesión del 13 de agosto de 1851, se asentó la comunicación formal que se había hecho con las autoridades eclesiásticas en el tema.

${ }^{16}$ El Congreso michoacano recibió, al respecto del proyecto sobre obvenciones parroquiales, cartas de apoyo de los municipios de Zitácuaro, Maravatío, Los Reyes, Apatzingán y Paracho. Véase Congreso del Estado de Michoacán, sesiones de 16 de junio, 2, 4, 9 y 11 de julio, y 27 de agosto de 1851, AHCEM, actas públicas.

${ }^{17}$ Las actas de cabildo pueden consultarse en los Libros de Acuerdos del Cabildo de Catedral, que están resguardados en el Archivo del Cabildo Catedral de Morelia (ACCM). Para la presente investigación, nos servimos de los libros 61 al 64, correspondientes a 1851-1861.
} 
La única respuesta por parte de la Iglesia se recibió en el Congreso de Michoacán el 4 de septiembre de 1851. En una carta escrita por Clemente de Jesús Munguía - en su calidad de vicario capitular-, explicaba la imposibilidad de discutir el tema de las obvenciones parroquiales debido a que existía sede vacante en el obispado, situación que impedía cualquier "innovación" en temas relacionados con la Iglesia y sus prerrogativas. Como responsable de la postura de la Iglesia, siendo Munguía además “...el miembro más polémico de la jerarquía eclesiástica de la época de la Reforma", ${ }^{18}$ a él se debe no dar importancia a la propuesta del Congreso michoacano, evadiendo discutir del tema y así evitar una reforma. Esta postura se contrapone a la opinión de Palo Mijangos González, en el sentido de que el Munguía de 1851-1852 no era aún un opositor "intransigente", sino que más bien, “...buscó fortalecer la cooperación recíproca entre la Iglesia y el gobierno civil durante sus primeros años al frente de la diócesis de Michoacán...". ${ }^{19} \mathrm{Al}$ contrario, con el asunto aquí tratado se revela que no había disposición por parte de la Iglesia michoacana para discutir un tema, como el de las obvenciones, que implicaba debatir sobre ámbitos de competencia de un asunto que, desde la visión del Legislativo estatal, debía reformarse.

El 3 de febrero de 1852, el destacado periodista y entonces diputado liberal Gabino Ortiz, propuso exigir a la Iglesia una respuesta definitiva sobre el tema de los aranceles, pues para esa fecha ya existía obispo electo; ${ }^{20}$ Munguía había tomado posesión el 18 de enero de ese año. No hubo respuesta y el asunto se quedó sin solución, además, porque en pocas semanas terminó trabajos la legislatura que impulsó el proyecto de reforma. La evidencia apunta a que la Iglesia en Michoacán no pretendía discutir asuntos que, siguiendo el pensamiento de Munguía al respecto, consideraba exclusivamente de su

\footnotetext{
${ }^{18}$ Pani, Iglesia, Estado y reforma, p. 53.

${ }^{19}$ Mijangos, Clemente de Fesús Munguía, p. 186.

${ }^{20}$ Congreso del estado de Michoacán, sesión del 3 de febrero de 1852, AHCEM, actas públicas.
} 
competencia. Y más que una postura retrógrada -según opiniones vertidas al interior del congreso michoacano-, debe tomarse como natural y razonable el que la Iglesia rehusara discutir un tema que implicaba, evidentemente, un examen de su relación con el Estado, máxime si para entonces se había dado un relevo en el gobierno estatal, designándose como ejecutivo a Melchor Ocampo, de quien se asumía un liberalismo radical.

La política michoacana durante los meses del gobierno de Ocampo -de junio de 1852 a enero de 1853-, estuvo condicionada por un contexto nacional desfavorable, determinado por problemas económicos del gobierno de la República, por los conflictos entre el presidente Arista y el Congreso de la Unión ${ }^{21}$ y por una revuelta que, aunque comenzó por un asunto doméstico en Jalisco, terminó extendiéndose a grado tal, que derivó en la dictadura de Antonio López de Santa Anna.

Y aunque Ocampo intentó llevar a cabo varias medidas reformistas ${ }^{22}$ debió ocuparse más por mantener vivas las instituciones republicanas. ${ }^{23}$ El 16 de septiembre de 1852, en alusión al inicio de la lucha por la Independencia, el liberal pronunció un discurso donde expuso puntos esenciales de la política del momento. Sentenció la necesidad de observar la igualdad, principio político al que catalogó como un derecho civil. Habló del individualismo como garante de la libertad de ciudadano, y lanzó una severa crítica a los conservadores,

${ }^{21}$ Sordo Cedeño, El Congreso, p. 141.

${ }^{22}$ Ocampo señaló como objetivos de su gobierno, el “...hacer que prospere la agricultura y minería, nuestros artefactos y nuestras relaciones mercantiles, esforzándonos en desestancar la propiedad, disminuir los gravámenes, mejorar los caminos, aprendiendo y aplicando las ciencias y artes que a esto conducen”. Obras completas, tomo III, p. 32.

${ }^{23}$ Desde el pueblo de Pátzcuaro, a pocos kilómetros de Morelia, los pronunciados que seguían la revuelta de Jalisco organizaron un pronunciamiento con protesta escrita, que desconoció al gobierno de Ocampo. Véase "Proclama de Francisco Bahamonde", Pátzcuaro, 29 de octubre de 1852, ACCM, 4-4.3-191-38. 
al señalar que, como Lucas Alamán, requerían un "amo" porque no eran capaces de gobernarse a sí mismos; hizo alusión al apoyo dado por ellos a Antonio López de Santa Anna. También, señaló que el mayor de los peligros de la patria era la pérdida de la libertad, pues el país aparecía en debilidad evidente, y era viable en este escenario que alguna nación extranjera decidiese invadir, tal y como había sucedido en 1846-1848 con la invasión norteamericana. Por esto sentenció: "Es hablando, no matándonos, como habremos de entendernos". ${ }^{24}$

El epílogo del gobierno de Ocampo fue determinado por la revuelta iniciada en Jalisco y la propia situación nacional. ${ }^{25}$ Hacia enero de 1853, sólo la ciudad de Morelia era controlada por el gobierno. Con fuerzas militares limitadas, Melchor Ocampo renunció al cargo de gobernador de Michoacán. A partir de entonces y con el Congreso local desarticulado, ${ }^{26}$ el gobierno local estuvo a cargo del coronel José

${ }^{21}$ Sordo Cedeño, El Congreso, p. 141.

${ }^{22}$ Ocampo señaló como objetivos de su gobierno, el “...hacer que prospere la agricultura y minería, nuestros artefactos y nuestras relaciones mercantiles, esforzándonos en desestancar la propiedad, disminuir los gravámenes, mejorar los caminos, aprendiendo y aplicando las ciencias y artes que a esto conducen”. Obras completas, tomo III, p. 32.

${ }^{23}$ Desde el pueblo de Pátzcuaro, a pocos kilómetros de Morelia, los pronunciados que seguían la revuelta de Jalisco organizaron un pronunciamiento con protesta escrita, que desconoció al gobierno de Ocampo. Véase "Proclama de Francisco Bahamonde", Pátzcuaro, 29 de octubre de 1852, ACCM, 4-4.3-191-38.

${ }^{24}$ García Granados, El esplendor, pp. 93-101.

${ }^{25}$ En carta a Ocampo, Guillermo Prieto, decía que: “... las aduanas del sur las ocupan los revolucionarios; las del norte producen bien poco y sus rendimientos se dedican a pagos urgentísimos militares. La aduana de Veracruz hundida entre consignaciones, pago de la deuda exterior y las fuerzas del mando de Robles, da sobre noventa mil pesos cada mes para todos los gastos del distrito. ¿Y las contribuciones?, están hipotecadas hasta enero por mis antecesores; y el tabaco, etc., etc., y todo está así...”. Obras completas, tomo IV, p. 45.

${ }^{26}$ Los diputados intentaron mantener el gobierno, nombrando un nuevo gobernador y desconociendo a las autoridades de facto; todo fue inútil. Congreso de Michoacán, sesiones de los días 26, 27 y 28 de enero de 1853, AHCEM, actas públicas. 
Bravo Ugarte, quien solemnizó la entrada del ejército insurrecto a la ciudad de Morelia el 1 de febrero de $1853 .{ }^{27}$ Lo anterior se daba a pocas semanas de la llegada de Antonio López de Santa Anna a México, quien había sido invitado a gobernar el país por miembros del auto declarado partido conservador, encabezados por Lucas Alamán. ${ }^{28}$

Bravo Ugarte sorteó varias dificultades, entre otras la falta de recursos ${ }^{29}$ y una lucha política intensa, que se observó con la aparición de "pasquines" liberales y escritos conservadores en franco conflicto entre ambos proyectos de gobierno.

A unos días de establecido el gobierno de Santa Anna, algunos intelectuales de Morelia expresaron por escrito su adhesión al régimen santanista. Expusieron su aversión al federalismo y al partido liberal que apoyaba un sistema que, dijeron, impedía la paz y la felicidad. A la par de esta y otras posturas similares, el conservador Ugarte solía encontrar en el bolsillo de su levita ejemplares de El Espectro, un periódico publicado de forma clandestina por varios conspicuos liberales,$^{30}$ que criticaba la postura conservadora, exaltándose, además, las bondades del proyecto reformista. Al tiempo que esto ocurría, los conservadores hacían su propia lucha propagandística en Michoacán con La Restauración, un panfleto destinado a publicitar las medidas de organización del gobierno conservador en Michoacán, toda vez que se aprovechaba el líbelo para descalificar a los liberales; decían que eran personas poco instruidas y seguidoras de ideas fantásticas

\footnotetext{
${ }^{27}$ Se publicó entonces un decreto para solemnizar el acto, prohibiéndose los "mueras" al ejército "restaurador". Coromina, Recopilación, tomo XIII, p. 19.

${ }^{28}$ Alamán explicó a Santa Anna, en una carta por demás elocuente, del proyecto conservador. Véase: González, Historia, pp. 309-311.

${ }^{29}$ Para sortear la problemática, pidió prestado; la Iglesia michoacana le otorgó tres mil pesos de forma inmediata. Acuerdos del Cabildo Eclesiástico, sesión de 11 de febrero de 1853, АCCM.

${ }^{30} \mathrm{El}$ periodista Mariano de Jesús Torres, afirma que una señora que trabajaba de costurera en la casa del gobernador era la responsable de colocar el periódico en las pertenencias del Ejecutivo estatal. Torres, Diccionario, tomo II, p. 327.
} 
-y fanáticas- de libertad. De tal suerte, el régimen de Santa Anna significó para los actores políticos en Michoacán, una oportunidad de enfrentamiento más que de conciliación.

\section{Reforma y constitución}

El régimen del dictador Santa Anna terminó en agosto de 1855. Juan Álvarez, quien había encabezado la Revolución de Ayutla, fue designado presidente de la República. ${ }^{31}$ En varias entidades comenzó entonces la reorganización del gobierno. En Michoacán se nombró un gobernador interino y se formó un consejo de gobierno, que fue integrado por liberales, pertenecientes a la intelectualidad y la política locales: Onofre Calvo Pintado, Luis Hinojosa, Agustín Tena, Miguel Silva Macías y Miguel Zincúndegui. El nuevo gobierno aprovechó las fiestas patrias de septiembre de 1855 para favorecer un sentimiento de unidad; ${ }^{32}$ ese mismo mes se promulgó el Estatuto Orgánico del estado de Michoacán, ${ }^{33}$ documento signado en atención al Artículo $3^{\circ}$ del Plan de Ayutla, que había sido la base del levantamiento en contra de Santa Anna.

En 14 artículos, en el estatuto se atendía el tema de la soberanía del estado de Michoacán frente a otras entidades, observando, a su vez, las disposiciones de la ley general. Se reafirmaba con suma atención el respeto a la libertad e igualdad, la seguridad y la propiedad, así como el derecho a la libertad de expresión. Estas cuestiones remiten a los axiomas centrales del liberalismo occidental, lo que permite asumir que los encargados de dirigir la política en Michoacán, en esos momentos, manejaban no solo los principios de la doctrina, sino

\footnotetext{
${ }^{31}$ Melchor Ocampo escribió que no estaba muy de acuerdo en que el experimentado militar se hiciera de las riendas del país: “...la suprema magistratura es una comisión de difícil desempeño, y no una recompensa de buenos servicios...”. Obras completas, tomo IV, pp. 213-229.

32 Véase La junta patriótica, 1855.

${ }^{33}$ El documento puede verse en Coromina, Recopilación, tomo XIII, pp. 30-32.
} 
que los postularon en los documentos rectores en el camino de la (re) estructura política nacional. No obstante, en el estatuto se dejó intacto el culto, al determinar la defensa de la fe católica como medida prioritaria, una postura que debe entenderse por pragmatismo y conveniencia política.

El 23 de noviembre de 1855 comenzó jurídicamente la reforma política en México. Ese día, en su calidad de ministro de Justicia y Asuntos Eclesiásticos del gabinete del presidente Juan Álvarez, Benito Juárez publicó la Ley sobre Administración de Justicia y Orgánica de los Tribunales de la Nación, del Distrito y Territorios. Conocida como Ley Juárez, la norma contiene los principios de la igualdad social al eliminar la posibilidad de que las corporaciones civiles y eclesiásticas - en concreto el Ejército y la Iglesia-, tuvieran tribunales especiales que juzgaran a sus miembros por delitos que correspondían al ramo civil. ${ }^{34}$

La medida dio inicio a amplios debates en varios puntos del país. Destaca la recia actividad a nivel político de miembros distinguidos de la Iglesia, entre estos algunos obispos, quienes rechazaron la medida por considerarla improcedente e innecesaria, en principio porque las prebendas de la Iglesia provenían de orden divino, fuera del alcance de lo que entonces llamaron "gobiernos temporales", y si alguna disposición civil se relacionaba a la curia, en todo caso debía consultarse con la Santa Sede, en Roma.

El obispo de Michoacán, Clemente de Jesús Munguía se opuso a la medida al considerar que atentaba contra el fuero eclesiástico. En una comunicación fechada el 30 de noviembre de 1855, Munguía solicitó a Benito Juárez la suspensión de al menos los Artículos 42, 44, y el transitorio $4^{\circ}$, que eran justamente los que referían a la Iglesia. ${ }^{35}$ Juárez no atendió la solicitud de Munguía, no obstante, la Ley Juárez no se aplicó, al menos en Michoacán, debido principalmente a las desfavorables condiciones políticas, ya que la sociedad se polarizó en

34 Tamayo, Juárez. Documentos, tomo 2, documento 17.

${ }^{35}$ Munguía, Defensa eclesiástica, pp. 2-4. Tamayo, Fuárez. Documentos, tomo 2, documento 27. 
torno al propio proyecto liberal y su contraparte conservadora, lo que hizo imposible cualquier acción al respecto.

En este escenario, el médico José María Manzo Cevallos, amigo íntimo de Melchor Ocampo, fue designado Ejecutivo de Michoacán en un ambiente que él definió de desastroso, pues el ramo de hacienda se encontraba en un estado lamentable: “...todo anda a la diabla [decía Manzo a Ocampo], y sin un peso con qué hacer los gastos, y el mal no es de momento, sino que están las rentas empeñadas hasta el mes de marzo. ¿Qué tal?”. ${ }^{36}$ Y eso no era todo, pues la política interna era sumamente desfavorable, agravada por acciones de grupos que se oponían al régimen político en turno. En enero de 1856 ocurrió una asonada en Morelia encabezada por la guarnición de Morelia, que no prosperó. ${ }^{37}$ En círculos políticos se difundió la idea de la participación del clero michoacano en el intento de insurrección, el cual había llegado al extremo de realizar críticas al gobierno, directas y públicas, durante las ceremonias religiosas. Esto ocasionó brotes radicales, como el del general michoacano Manuel García Pueblita, quien intentó saquear la iglesia catedral de Morelia, acción que finalmente no se llevó a cabo, empero, que polarizó aún más las relaciones entre la Iglesia y el gobierno liberal de Michoacán.

En mayo de 1856 hubo relevo en el gobierno local, siendo designado gobernador otro médico: Miguel Silva Macías, quien trabajó en consonancia al proyecto del Centro. Promulgó en Michoacán el Estatuto Orgánico Provisional de la República, expedido el 30 de mayo por el entonces presidente, Ignacio Comonfort; decretó medidas sobre el cobro de impuestos y nombró abogados especiales, intentando arreglar los pleitos que entonces se daban en comunidades indígenas. En otras cosas, Silva Macías llevó a cabo acciones que pueden interpretarse como de ataque en contra de la Iglesia, al ordenar la modificación de diversos parajes y solares pertenecientes al clero, ocupando

\footnotetext{
${ }^{36}$ Arreola Cortés, Obras completas, tomo IV, pp. 209-210.

37 Torres, Diccionario, tomo II, p. 355.
} 
además las huertas de los conventos de San Francisco y San Agustín en Morelia.

A Silva Macías tocó también promulgar en el territorio la Ley de desamortización de fincas rústicas y urbanas (Ley Lerdo), promulgada el 25 de junio de $1856 .{ }^{39}$ En el decreto -ampliamente difundido en Michoacán-, se señaló que se haría desaparecer el error económico que significaba mantener estacionada la propiedad, impidiendo el desarrollo de las artes y la industria nacionales, se dijo entonces que la medida tenía objeto de "....allanar el principal obstáculo que hasta hoy se ha presentado para el establecimiento de un sistema tributario, uniforme y arreglado a los principios de la ciencia, movilizando la propiedad raíz, que es la base natural de todo buen sistema de impuestos...". 40

Al igual que la Ley Juárez, la de desamortización fue objeto de severas críticas. Una de estas provino del obispo de Michoacán, Clemente de Jesús Munguía. El 16 de julio de 1856, el prelado publicó un texto donde pedía la derogación de la ley pues, en su opinión, violaba la independencia y soberanía de la Iglesia. Su carta no tuvo ánimo de lucha política, puesto que dijo protestar "respetuosamente" contra el decreto, "...no contra las obligaciones que tenemos todos para con el gobierno temporal". ${ }^{41}$

En el pensamiento de Munguía las leyes Juárez y Lerdo violentaban las relaciones con el Estado, además porque asumía prerrogativas que no le correspondían frente a una institución soberana, de ahí su oposición a estas y a las subsecuentes disposiciones reformistas. ${ }^{42}$ En tanto, para los actores de la política nacional, las medidas significaban el impulso a la libertad ante la ley, axioma fundamental del pensamiento liberal como ya se ha dicho, además de favorecer la

\footnotetext{
${ }^{39}$ Para el caso de Michoacán, véase Rivera Reynaldos, Desamortización y nacionalización, 210 pp.

${ }^{40}$ Silva, Consejero Decano, s./p.

${ }^{41}$ Munguía, Defensa, p. 23.

${ }^{42}$ Mijangos, Clemente de Jesús Munguía, p. 186.
} 
creación de pequeños propietarios, aunado esto al hecho de que, con tales medidas, podía disminuirse el poder e influencia política, económica e ideológica de la Iglesia. ${ }^{43}$

No solo la clase política participaba de los debates en torno a la construcción del Estado. Desde diversos sectores sociales, a veces en un ánimo radical, se opinó ampliamente sobre los temas que estaban en discusión en el centro político nacional. Por entonces, el Congreso Constituyente sesionaba en la capital del país, y cuando se debatió el Artículo $15^{\circ}$ relacionado con la tolerancia de cultos, en Michoacán se sucedieron las voces de rechazo.

El asunto no era en realidad nuevo. En el proyecto que Ocampo condujo en 1851 al Congreso michoacano, había señalado seguir las "intuiciones de la conciencia" en referencia a las creencias religiosas y a la libertad que, consideraba, tenía el individuo para creer en lo que su conciencia le dictase. El asunto es que, de aprobarse el Artículo $15^{\circ}$ habría de establecerse por ley la libertad de creencias religiosas y con esto, permitir el establecimiento de otras religiones en México. En Michoacán, grupos pertenecientes a la sociedad letrada y, sobre todo, mujeres organizadas, se inconformaron por considerar que se atentaba contra la moralidad del pueblo de México. Por medio de cartas enviadas al Congreso Constituyente, se presionó para que en el proyecto de Constitución no se incluyera el tema.

En julio de 1856 circularon varios escritos en Michoacán, firmados por parte de la intelectualidad michoacana; dos de ellos signados por "señoras respetables". El contenido de las misivas era de rechazo a que se permitiese otra religión en el país, puesto que la católica era la única verdadera, y además, garantizaba los derechos de las personas como ninguna otra podía hacer. Se enfatizó en que la Iglesia estaba en todo su derecho a determinar en el hombre dogmas y doctrinas, pues ella era la depositaria de los derechos divinos. ${ }^{44}$

${ }^{43}$ Pani, Iglesia, Estado y reforma, pp. 50-51.

${ }^{44}$ Exposición, s./p. 
La cuestión es interesante, en primera, porque se demuestra que la sociedad en provincia estaba pendiente de la política dictada en el centro; segundo, porque dicha sociedad estaba atenta, sobre todo, de los elementos en disputa relacionados con su imaginario religioso, y ante el peligro de modificación de su entorno, se prestaba a su defensa. ${ }^{45}$

El 5 de febrero de 1857 se promulgó la nueva Carta Magna. En marzo, el presidente Comonfort expidió un decreto que ordenó que fuera obligatorio el juramento a autoridades y empleados en todo el país; se dio carácter al hecho como de festividad nacional. ${ }^{46}$ Esto, sostiene Erika Pani, y con razón, significaba mostrar que el gobierno civil tenía autoridad en la conciencia del individuo. ${ }^{47}$

En Michoacán, el gobernador en turno Miguel Zincúndegui-que había sucedido temporalmente a Miguel Silva Macías-, publicó el decreto que ordenaba observar el juramento a la Constitución en el territorio estatal, que se haría de forma solemne y escalonada, es decir, de acuerdo con el rango administrativo, al jefe inmediato; la fórmula llegaba hasta el nivel de ayuntamientos, en cuyo caso, el alcalde debía jurar ante el regidor decano y luego tomaba el juramento a los miembros de la municipalidad. ${ }^{48}$

En respuesta a la medida, Clemente de Jesús Munguía expidió una circular en la que sostenía que la obligación al juramento era una norma indebida, y aquellos que jurasen acogerían el castigo de no recibir los sacramentos, al menos hasta su retractación pública. Por su parte, el gobierno del estado determinó que los funcionarios que no acatasen las disposiciones serían retirados del servicio público.

\footnotetext{
${ }^{45}$ El caso michoacano es uno de varios que ocurrieron en el país, en torno al debate en torno al Artículo $15^{\circ}$ del proyecto de Constitución. Véase Pani, Iglesia, Estado y reforma, pp. 46-48.

${ }^{46}$ El decreto apareció el 17. Puede verse en Dublán y Lozano, Legislación, tomo 8, pp. 426-427.

${ }^{47}$ Pani, Iglesia, Estado y Reforma, p. 48.

${ }^{48}$ Coromina, Recopilación, tomo xIII, pp. 64-65.
} 
Esto puso en contradicción la vida de los mexicanos, que debieron decidir su vida pública entre la religión heredada y su responsabilidad como ciudadanos. En esto incurrió Francisco Orozco, empleado municipal de Morelia, quien el 1 de abril de 1857 hizo público un documento donde se desdecía del juramento, argumentando que era mejor el sacrificio de quedarse sin trabajo a contravenir los deberes de su conciencia, que le indicaban respetar la religión de sus padres. ${ }^{49}$

El contexto se agravó en la capital del estado y en las municipalidades, pues la opinión pública se dividió en opositores y simpatizantes del texto constitucional. En Morelia, el 30 de marzo de 1857, circuló un documento - anónimo- donde se reflexionaba críticamente respecto a los Artículos $3^{\circ}, 5^{\circ}, 6^{\circ}, 7^{\circ}, 13^{\circ}, 27^{\circ}$ y $123^{\circ}$. Todos, de alguna forma, afectaban a la Iglesia, pues hacían referencia a la educación, que debía ser responsabilidad exclusiva del Estado; la "disolubilidad del matrimonio"; la libertad de expresión y la imposibilidad de que miembros de la Iglesia adquirieran bienes inmuebles, entre otras cosas. Los vecinos de Pátzcuaro, por ejemplo, decían que México no quería la Constitución:

...por autocrática; la rechaza, por impía; la mira con indignación, porque ataca la autoridad y los derechos de la Santa Iglesia; se horroriza con ella, porque no reconoce religión alguna, porque las tolera a todas, porque destierra la católica, la única verdadera, la única que ha profesado el país y en cuyo seno quiere se alimenten las edades venideras $[\ldots]$ Las constituciones que entrañan y sostienen el catolicismo, establecen el orden, hacen buenos a los hombres y felices a las naciones. ${ }^{50}$

El juramento acentuó la polarización política en el país, agravándose el contexto con la promulgación, el 11 de abril de 1857, de la ley que

${ }^{49}$ Retractación, 1 de abril de 1857, ACCM, 5-5.5-58-78.

${ }^{50}$ Manifestación, s./p. 
estableció los aranceles parroquiales para el cobro de derechos y obvenciones, que coincidió en Michoacán con la convocatoria para la elección de diputados a la legislatura constituyente y gobernador del estado, toda vez que al mismo tiempo se daba otra polémica, esta vez entre los abogados eclesiales José Guadalupe Romero y Ramón Camacho, y el magistrado michoacano Manuel Teodosio Alvírez, quien refutó la supuesta independencia de la Iglesia sosteniendo que los curas y las dignidades eclesiásticas estaban dentro del Estado, por lo que eran ciudadanos con el pleno derecho de sus obligaciones. Enfático, señaló que la Constitución no contravenía la religión, solamente ponía en su lugar el culto y la autoridad civil. ${ }^{51}$

En cuanto a la Ley Iglesias, como se llamó a la de obvenciones, estableció que los sacerdotes debían cobrar por bautismos, amonestaciones, casamientos y entierros, solo lo establecido en las leyes canónigas de 1746, además, establecía la exención del pago a pobres y menesterosos. ${ }^{52}$

Se ordenó que el decreto fuese ubicado en los cuadrantes de pueblos y ciudades de México para su observancia. En Michoacán, debido a reacciones de rechazo, la autoridad debió pegar por la fuerza los documentos; aun así, manos invisibles quitaban las circulares del gobierno donde antes había anuncios eclesiásticos. Sucedió entonces una lucha sigilosa de poderes, que causó destierro de curas y la suspensión de oficios religiosos como señal de duelo.

La situación evidenciaba una separación peligrosa entre las posturas de los sectores influyentes de la sociedad mexicana. Para entonces se habían definido con precisión los partidarios del liberalismo, conocidos como jacobinos en alusión a los que encabezaron la Revolución francesa, y los conservadores. Siguiendo la normativa del centro, en las provincias trabajaban los Congresos constituyentes, en los textos normativos de cada entidad. En Michoacán, el Congreso se

${ }^{51}$ Reflexiones, s./p.

${ }^{52}$ El decreto puede verse en Dublán y Lozano, Legislación, tomo 8, pp. 431-432. 
conformó por ocho diputados, todos simpatizantes del liberalismo. Se designó a Santos Degollado como gobernador y, aunque no tomó posesión de inmediato, su nombramiento aparecía en función del proyecto del centro político nacional.

Así, en medio de críticas por parte de los sectores afines al partido conservador, en Michoacán se promulgó la Constitución local, la cual, según sus creadores, cumplía con el "sagrado compromiso" que se había contraído con la sociedad, ya que en el texto se observaban los "preciosos derechos" consignados en la Constitución de la República. ${ }^{53}$

Lo que siguió llevó al país a un amplio conflicto, ya que el 17 de diciembre de 1857, Ignacio Comonfort dio un golpe de Estado en la ciudad de México, eliminando los poderes de la República e inaugurando la etapa más sangrienta de la vida política de México: la Guerra de los Tres Años. ${ }^{54}$

\section{Epitacio huerta y el liberalismo radical en Michoacán}

La legislatura de Michoacán desconoció a Comonfort en su calidad de presidente de México. Tal acción ocurrió en consonancia con los miembros del Congreso de la Unión quienes, en respuesta al golpe de Estado, habían incitado a los gobiernos de provincia a rechazar el Plan de Tacubaya, ${ }^{55}$ apoyando consecuentemente al sostenimiento del orden constitucional; enmedio del conflicto emergió la figura de Benito Juárez García, quien entonces se desempeñaba como presidente de la Suprema Corte de Justicia.

${ }^{53}$ Coromina, Recopilación, tomo XVI, pp. 36-37.

${ }^{54}$ En Michoacán se sabía con antelación de la conspiración. Epitacio Huerta había recibido una invitación de Félix María Zuloaga, jefe de la guarnición de la capital, y Manuel Payno, ministro de Hacienda de Comonfort, para unirse a la sublevación. Ante esto, el general dio aviso al gobierno local, mientras que el diputado por Michoacán, Eligio Sierra, hacía lo propio en el Congreso general, en la sesión del 14 de diciembre de 1857. Arreola Cortés, Epitacio Huerta, p. 29.

${ }^{55}$ Dicho plan fue la bandera de los sublevados. Once entidades apoyaron el documento de inmediato, y ocho lo rechazaron en un inicio, Michoacán fue uno de ellos. 
La posición del gobierno de Michoacán en aquellos momentos fue de apoyo a Juárez, quien instituyó un gobierno itinerante, que luego de un sinuoso trayecto,${ }^{56}$ pudo asentarse en Veracruz, desde donde se promulgaron las conocidas Leyes de Reforma. En estas condiciones, el presidente estuvo de cierta manera supeditado al apoyo de los gobernadores, en quienes recayó la responsabilidad de rescatar al gobierno liberal, por esto, Juárez debió observar una política sumamente inteligente de cara al protagonismo de los ejecutivos estatales. ${ }^{57}$

Varios estados formaron coaliciones de apoyo al gobierno constitucional encarnado en Benito Juárez; Michoacán fue uno de ellos. Santos Degollado, ${ }^{58}$ quien había tomado posesión del gobierno local el 24 de diciembre de 1857, encausó las intenciones que, desde los líderes militares locales - entre ellos el destacado general Epitacio Huerta- ${ }^{-59}$ y desde varios municipios de la entidad ${ }^{60}$ habían surgido en defensa de la Constitución. ${ }^{61}$

Degollado inició una serie de medidas extraordinarias para hacerse de recursos. Primero, decretó un préstamo de carácter forzoso al clero de Michoacán; el argumento fue que era preciso garantizar la unidad nacional, y mantener la paz y el orden. ${ }^{62}$ La respuesta del obispo fue de rechazo, y aunque -mediante presiones políticas- se logró que Degollado derogara el decreto que establecía el préstamo, el gobernador promulgó otro, donde imponía una revisión obligatoria

\footnotetext{
${ }^{56}$ Entre marzo y mayo de 1858, Juárez hizo gobierno en Colima, Guadalajara -donde estuvo a punto de morir- y Manzanillo, viajó por barco a Panamá y luego en tren a las costas del Golfo, luego se dirigió a la Habana y de ahí a Nueva Orleans, para después dirigirse a su destino final, Veracruz.

${ }^{57}$ Hamnett, Fuárez, p. 95.

${ }^{58}$ Sobre la vida política de Degollado, véase Mercado Villalobos, Santos Degollado, pp. 37-66.

${ }^{59}$ Congreso de Michoacán, sesión del 24 de diciembre de 1857, AHCEM, actas públicas. ${ }^{60}$ Véase El Pueblo, 28 de diciembre de 1859.

${ }^{61}$ Por defender la Constitución, al ejército organizado en apoyo de Juárez se le denominó constitucionalista.

${ }^{62}$ Coromina, Recopilación, tomo XIV, pp. 28-29.
} 
de las contribuciones personales sobre sueldos y salarios, de las altas dignidades eclesiásticas. ${ }^{63}$

Las medidas recaudatorias se extendieron aún más. Para montar la tropa que debía salir a campaña, el 2 de enero de 1858, Degollado decretó un préstamo aplicable a las haciendas y fincas rústicas de los distritos de Puruándiro, Jiquilpan, Maravatío, Ario, Huetamo, Apatzingán y La Piedad. El préstamo, de carácter forzoso, podía darse en caballos o dinero; días después apareció otro decreto, que establecía gravámenes al comercio de Morelia.

Santos Degollado dejó el gobierno de Michoacán para integrarse al gabinete de Benito Juárez - estarían también Melchor Ocampo, Guillermo Prieto, Manuel Ruiz y León Guzmán-, por este motivo, Miguel Silva Macías quedó investido como jefe del Ejecutivo estatal, sin embargo, las circunstancias de guerra obligaron a que un militar, el general Epitacio Huerta, se ocupara del gobierno. Huerta encabezó un gobierno radical, caracterizado por llevar a cabo acciones tendientes a sostener al gobierno de Juárez, además, intentó a toda costa aplicar en Michoacán las Leyes de Reforma impulsadas por los liberales.

El 12 de marzo de 1858, el gobernador Huerta decretó el estado de sitio en Michoacán, y ordenó la suspensión de las funciones de las autoridades estatales, además, reasignó el poder público en todos los ramos de la administración a su persona. Resulta interesante el comentario que el mismo general hizo en torno a su gobierno, al señalarlo como una dictadura, necesaria, dijo, para afrontar la situación extraordinaria que entonces se vivía. Fue severo con los conservadores, pero también con varios michoacanos del partido liberal, quienes intentaron

${ }^{63}$ Degollado conocía las finanzas de la Iglesia michoacana pues había trabajado en la haceduría de la Catedral de Morelia por poco más de veinte años. De esta manera, conocía que obispos y capitulares adeudaban dinero a la hacienda pública por concepto de contribución directa, de la cual solo se había pagado una "buena cuenta". Los préstamos forzosos a la Iglesia fueron comunes por parte del Estado en Michoacán. Moisés Guzmán Pérez hace un recuento en su trabajo sobre Cayetano Gómez de Portugal. Véase Guzmán, Las relaciones clero-gobierno, 251 pp. 
manejar su gobierno, de ahí que su mandato fuese determinado por un carácter eminentemente radical. ${ }^{64}$ Muestra de ello es que, durante su gestión, para allegarse recursos, Huerta impuso hasta veintinueve préstamos forzosos a distintos sectores de la sociedad michoacana, incluyendo por supuesto a la Iglesia. ${ }^{65}$

Precisamente, Huerta impuso medidas mayormente severas al Cabildo Eclesiástico, tendientes a disminuir su poder económico. Decretó varios préstamos en tanto que presionaba con amenazas de ocupación de los bienes de la Iglesia. ${ }^{66}$ El 6 de junio de 1858 expidió un decreto que gravaba los capitales de manos muertas, medida que justificó en tanto se restablecía el orden constitucional. ${ }^{67}$ Esto fue interpretado por las autoridades eclesiásticas como violatoria a sus derechos, por lo que el obispo fijó una postura pública de crítica a las medidas del gobierno liberal michoacano. Huerta contestó imponiendo una multa de 500 pesos, cantidad que habría de descontarse de la deuda que el gobierno tenía con la Iglesia. ${ }^{68}$

Las fricciones con el clero las llevó el general a su máximo nivel al ordenar la ocupación de la iglesia catedral de Morelia. Huerta había solicitado al Cabildo Eclesiástico un préstamo por 90,000 pesos, mismo que le fue negado. En respuesta, la madrugada del 22 de diciembre de 1858 fue sitiada la ciudad por la guarnición local, y por cinco días, un grupo de plateros - que habían sido reclutados mediante leva- se encargaron de desmontar oro y plata de nichos y altares del interior del recinto; el objetivo, además de tener un fin político conforme con

${ }^{65}$ Los decretos recaudatorios aparecen en: Coromina, Recopilación, tomo xv, pp. 4, 7, $9,12,13,15,19,20$ у 26.

${ }^{66}$ Se dieron embargos en los diezmatorios de Jungapeo, Tuxpan y Taximaroa, finalmente, el 16 de marzo de 1858, una tropa del gobierno ocupó el diezmatorio de Zinapécuaro, acción coincidente con las amenazas de gobernador para con la Iglesia michoacana. Acuerdos del Cabildo Eclesiástico, sesión del 16 de marzo de 1858, ACGM.

${ }^{67}$ Coromina, Recopilación, tomo XVI, pp. 5-6.

${ }^{68}$ Acuerdos de Cabildo Eclesiástico, sesiones de 29 de marzo y 30 de abril, ACCM. 
palabras del general, era económico, al utilizar el usufructo del metal para la causa liberal. ${ }^{69}$

Ante múltiples reclamos ciudadanos, Huerta había llevado el radicalismo de Estado hasta sus últimas consecuencias, toda vez que emprendía algunos proyectos sociales. Declaró gratuita la enseñanza, expidió una Ley del Hospital Civil a partir del cual, entre otras cosas, el Hospital de San Juan de Dios pasaba a manos del gobierno. ${ }^{70}$ Se ocupó también del histórico Colegio de San Nicolás, al decretar el restablecimiento de las cátedras de "ciencias médicas", además del otorgamiento de becas a estudiantes de escasos recursos. ${ }^{71}$

Para el liberalismo mexicano 1859 fue importante. Desde Veracruz Benito Juárez promulgó las Leyes de Reforma, no obstante, también fue un tiempo de destrucción y de pobreza generalizada. En La Bandera Roja, periódico liberal michoacano, se decía así del contexto nacional en enero de 1859:

Las ciudades y campos, incendiados; la propiedad destruida o violada; la seguridad perdida; la libertad aniquilada; la agricultura y el comercio paralizados; las vías de comunicación enteramente obstruidas; la miseria profundamente gravada; en una palabra, el luto, la desolación y el exterminio, extendidos en todos los ámbitos del territorio [...]. Méjico despedazado por la guerra civil, aniquilado por los fuertes choques de los partidos, reducido casi a la impotencia por la división en que se encuentran sus hijos, es una presa capaz de excitar la codicia de las naciones ambiciosas. ${ }^{72}$

\footnotetext{
${ }^{69}$ Meses después, se difundió que parte del botín se encontró en la casa del ministro norteamericano John Forsyth, quien dijo no saber su procedencia. La bandera roja, 3 de marzo de 1859 .

70 Coromina, Recopilación, tomo xv, pp. 37-45.

${ }^{71}$ Coromina, Recopilación, tomo xv, p. 56. La medida no pudo llevarse a cabo por falta de recursos.

${ }^{72}$ La Bandera Roja, 10 de enero de 1859.
} 
El corolario reformista en Michoacán fue la publicación, el 6 de agosto de 1859, de la Ley de Nacionalización de Bienes Civiles y Eclesiásticos. La reseña del acontecimiento publicada en La Bandera Roja es elocuente al respecto:

Mil quinientos hombres de todas armas acompañaron al Sr. Prefecto y al Ilustre Ayuntamiento en su publicación; después formaron columna de honor mandada por el Jefe de la brigada ciudadano general José María Arteaga, pasando por delante del seminario, en cuyo balcón se hallaba el E. S. Gobernador del Estado acompañado del general Pueblita y de muchas personas distinguidas del partido liberal: en seguida todas las tropas se dirigieron a la plaza de San José en cuyo cuadro estaban colocadas unas mesas debajo de la vela para que tomase la tropa un buen almuerzo que se le sirvió. En la puerta del cuartel el E. S. General D. Epitacio Huerta repartió una cantidad de dinero a los mutilados y a las viudas y huérfanos de los muertos en la actual lucha contra el nefando y detestable bando clerical. En un dosel preparado al efecto frente a la puerta del templo de San José se leyeron el manifiesto y proclamas del señor Huerta y se pronunciaron varios discursos ardientes y patrióticos que el pueblo entusiasmado aplaudió con frenesí. El paseo de la calzada estuvo en la tarde muy concurrido y la más pura alegría se pintaba en los rostros de todos los habitantes, demostrando que comprendían muy bien los decretos expedidos y los resultados benéficos que producirían al país. En la noche se iluminaron los edificios públicos y las músicas militares colocadas en la plaza principal y en la de San José tocaron piezas escogidas; muchos grupos de particulares recorrían toda la ciudad tocando alegres sonatas y cantando piezas hermosas y 
canciones agradables en las puertas de las casas de las familias liberales. ${ }^{73}$

La parte final de la Guerra de Reforma no tuvo un impacto militar sobresaliente en Michoacán, salvo las medidas políticas impulsadas por Epitacio Huerta. La prensa local dio cuenta de los principales sucesos del proceso de guerra, como las firmas de los tratados McLaneOcampo entre el "gobierno constitucional" de Juárez y el de Estados Unidos, ${ }^{74}$ y el Mon-Almonte, entre el "gobierno constitucionalista" de Miramón y España. También, se dio un seguimiento de las acciones militares y del liderazgo de Santos Degollado, general en jefe del ejército liberal, de quien Huerta desconfiaba al considerarlo poco apto para liderar la lucha hasta el triunfo, ${ }^{75}$ lo que comprobó cuando éste pretendió un arreglo para terminar la guerra, que difería en sus principios, con el grueso de los liberales. ${ }^{76}$

En el último año de guerra, Huerta decretó nuevas medidas recaudatorias, ahora hacia varios ayuntamientos de Michoacán. El 9 de junio de 1860 se impuso un préstamo obligado por 50,000 pesos, empero, que solo afectaría a "ciudadanos de comodidades"; 77 también, impuso ciertas medias en el ramo educativo. Finalmente, y buscando apoyar la causa nacional, Huerta renunció al cargo de gobernador de Michoacán dejando como interino a su hermano Antonio, quien en el poco tiempo que estuvo en el Ejecutivo, sólo vigiló mantener a flote el gobierno.

\footnotetext{
${ }^{73}$ La Bandera Roja, 8 de agosto de 1859.

${ }^{74}$ Véase Galeana, El tratado, 515 pp.

${ }^{75}$ Huerta y Degollado habían tenido un disgusto desde junio de 1859 con la designación de éste como gobernador. Por su parte, Degollado creía que Huerta no sabía más que tiranizar a Michoacán, y no quería unirse al campo de batalla. Arreola Cortés, Epitacio Huerta, p. 61.

${ }^{76}$ En el plan se establecía que representantes de otras naciones hicieran de árbitros en el conflicto, un asunto que, en opinión de líderes liberales, como el propio Benito Juárez, era inadmisible.

${ }^{77}$ Coromina, Recopilación, tomo Xv, pp. 138-141.
} 
Epitacio Huerta regreso a Michoacán y ocupó nuevamente la gubernatura del 12 de febrero al 15 de abril de 1861. En su informe final sobre su "dictadura", señaló que su periodo de gobierno había terminado, así como las "facultades extraordinarias" que habían caracterizado su mandato. Parecía que terminaba una etapa compleja e iniciaba la reconstrucción nacional, sin embargo, la muerte de Melchor Ocampo a manos de Leonardo Márquez, ocurrida el 3 de junio de 1861, era signo de que los problemas nacionales estaban lejos de terminar. Así, terminaba la etapa del liberalismo militante, para continuar enseguida la lucha por la permanencia del régimen liberal.

\section{Consideraciones finales}

El propósito de este artículo ha radicado en examinar actores y acciones en tanto a la imposición del proyecto liberal en Michoacán. Los motivos del examen se acordaron en función de la necesidad por revisar casos regionales, con respecto al proceso de reforma, a fin de apoyar la comprensión acerca de los ritmos de consolidación política del Estado mexicano durante el siglo xIx.

$\mathrm{Al}$ respecto, aunque de forma breve, quedó claro que, en un caso particular como el examinado, pueden percibirse los inicios del conflicto entre la Iglesia y el Estado, y de las maneras en que los actores locales interpretaron y llevaron a cabo acciones, sustentadas en la necesidad de constituir una sociedad política, siguiendo los parámetros del liberalismo occidental. De esto se deducen no solo las fuentes de formación política, evidentes en el lenguaje inmerso en las medidas reformistas, sino, también, las formas en que la Iglesia se defendió buscando la coexistencia con el propio Estado.

El estudio implica, también, no solo el reconocimiento de una polarización - en ocasiones excesiva- entre los sectores en disputa, sino también la existencia de un liderazgo político sumamente radical en Michoacán, que determinó una compleja posición a la sociedad, la cual, eminentemente católica, debió conciliar la tradición heredada con 
la aceptación de un gobierno cuyo proyecto de desarrollo nacional se contraponía, de alguna manera, a esa tradición religiosa.

Asimismo, la evidencia ofrecida permite señalar el hecho de que, en Michoacán, bajo el liderazgo de hombres vinculados con el partido liberal, las medidas reformistas impulsadas por el centro político -las Leyes de Reforma-, no solo se promulgaron en el territorio estatal, sino que se intentó su aplicación efectiva, lo que denota una actitud política radical en territorio michoacano. De esta manera, el trabajo remite a un complejo proceso, sustentado, no en la conciliación, sino en la imposición del proyecto liberal, lo que ocurrió en exacta alineación con el centro político, con los líderes del proyecto de transformación nacional. 


\section{Fuentes}

\section{Archivo}

Archivo Histórico del Congreso del Estado de Michoacán (AHCEM), actas públicas, 1851, 1852, 1853 y 1857.

Archivo del Cabildo Catedral de Morelia (ACCM), Acuerdos del Cabildo Eclesiástico, libros 61-64, de 1851-1861.

\section{Hemerografía}

La Bandera Roja, periódico político, Morelia, imprenta de Octaviano Ortiz e Ignacio Arango, 1859.

El Pueblo, periódico político, Morelia, imprenta de Octaviano Ortiz e Ignacio Arango, 1859.

\section{Impresos del siglo XIX}

Clemente de Jesús Munguía. Obispo de Michoacán, México, s./e., 5 de enero de 1858.

Coromina, Amador, Recopilación de Leyes, decretos, reglamentos y circulares expedidas en el Estado de Michoacán, Morelia, imprenta de los hijos de Ignacio Arango, tomo xIII, 1899.

Exposición que varios vecinos de Morelia elevan al soberano Congreso Constituyente, pidiéndole se digne reprobar el artículo $15^{\circ}$ del proyecto de Constitución sobre tolerancia de cultos, Morelia, imprenta de Ignacio Arango, 1856.

La junta patriótica de Morelia, a los habitantes de esta municipalidad, Morelia, imprenta de Ignacio Arango, 11 de septiembre de 1855. 
Manifestación que hacen los vecinos del partido de Pátzcuaro sobre la nueva Constitución, Morelia, imprenta de Ignacio Arango, 1857.

Memoria de Gobierno de 1861, Morelia, imprenta del gobierno, 1861.

Reflexiones sobre los decretos episcopales que prohiben el juramento, escritas por el C. Lic. Manuel T. Alvirez, Primer Magistrado y actual presidente del Supremo Tribunal de Justicia del Estado soberano de Michoacán, México, tip. de N. Chávez, 1857.

Silva, Miguel, Miguel Silva, Consejero Decano, encargado del gobierno de Michoacán, a todos sus habitantes, sabed, que, Palacio de Gobierno, Morelia, 3 de julio de 1856.

Torres, Mariano de Jesús, Diccionario histórico, biográfico, geográfico, estadístico, zoológico, botánico y mineralógico de Michoacán, Morelia, tipografía particular del autor, tomo III, 1915.

\section{Referencias bibliográficas y electrónicas}

Arreola Cortés, Raúl, Epitacio Huerta, soldado y estadista liberal, Morelia, Gobierno del estado de Michoacán, 1979.

, Obras Completas de Don Melchor Ocampo, Gobierno del estado de Michoacán, Morelia, tomo II, 1985.

Arrioja Díaz Viruell, Luis Alberto, "Pueblos, reformas y desfases en el sur de México: Oaxaca, 1856-1857", en Historia Mexicana, LXvI, 2, 2014, pp. 487-532.

Blázquez Domínguez, Carmen, Veracruz liberal 1858-1860, México, El Colegio de México, Gobierno del estado de Veracruz, 1986.

Dublán y Lozano, Legislación mexicana, México, Imprenta del Comercio, tomo 8, 1876 . 
Galeana, Patricia, El tratado McLane-Ocampo. La comunicación interoceánica y el libre comercio, México, Editorial Porrúa/cisan-unam, 2006.

García Granados, Eleazar, El esplendor de la elocuencia en México, Morelia, Sociedad de Nicolaítas Exalumnos, A. C., Universidad Michoacana de San Nicolás de Hidalgo, 1999.

González Laporte, Verónica, Leonardo Márquez, el "Tigre de Tacubaya", México, Editorial Las Ánimas, 2016.

Guzmán Pérez, Moisés, Las relaciones clero-gobierno en Michoacán. La gestión episcopal de Juan Cayetano Gómez de Portugal y Solís, 18311850, México, Congreso de la Unión, Cámara de Diputados, 2005.

Hale, Charles, El liberalismo mexicano en la época de Mora, México, Siglo Veintiuno Editores, 2005.

Hamnett, Brian, Juárez. El benemérito de las Américas, México, Colofón, S. A., 2006.

León Portilla, Miguel (edición), Historia documental de México 2, México, edición digital, unam, 2013. http://www.historicas.unam. $\mathrm{mx} /$ publicaciones/publicadigital/libros/historia_documental/ v02/593t2c_04_02_santa_anna.pdf [Consultado el 30 de enero de 2018].

Mercado Villalobos, Alejandro, "Santos Degollado. Estudio político de un liberal mexicano", en Tzintzun. Revista de estudios históricos, núm. 63, enero-junio del 2016, pp. 37-66.

Mijangos y González, Pablo, "Las vías de lo legítimo: derecho natural y estado católico en la obra de Clemente de Jesús Munguía”, en Cuadernos del Instituto Antonio de Nebrïa, 9, 2006, pp. 151-221. 
, "Clemente de Jesús Munguía y el fracaso de los liberalismos católicos en México (1846-1861)", en Brian Connaughton (coordinador), México durante la guerra de reforma. Tomo I. Iglesia, religión y Leyes de Reforma, México, Universidad veracruzana, 2011, pp. 167-198.

, The lawyer of the Church. Bishop Clemente de Jesús Munguía and the Clerical Response to the Mexican Liberal Reforma, Lincoln y Londres, University of Nebraska Press, 2015.

Munguía, Clemente de Jesús, Defensa eclesiástica en el Obispado de Michoacán, desde fines de 1855 hasta principios de 1858, Morelia, imprenta de Vicente Segura, tomo primero, 1858.

Núñez García, Víctor M., "Los orígenes del liberalismo mexicano. Elites y grupos de poder en Puebla (1833-1857)", Secuencia, núm. 78, septiembre-diciembre 2010, pp. 43-87.

Olveda, Jaime, Los obispados de México frente a la reforma liberal, México, El Colegio de Jalisco, 2007.

Ornelas Hernández, Moisés, "El obispo de Michoacán, Clemente de Jesús Munguía. ¿Escándalo o provocación política?”, https:// archivos.juridicas.unam.mx/www/bjv/libros/7/3100/20.pdf [Consultado el 24 de enero de 2018].

Pani, Erika, "Iglesia, Estado y reforma. Las complejidades de una ruptura", en Brian Connaughton (coordinador), México durante la Guerra de Reforma. Tomo I. Iglesia, religión y Leyes de Reforma, México, Universidad Veracruzana, pp. 41-67.

Pérez Daniel, Gustavo Herón, "El caso del liberalismo vidaurrista 18531859: hacia una historia intelectual de la política en Nuevo León", en Letras Históricas, núm. 6, primavera-verano 2012, pp. 95-115. 
Rivera, Flavio, Derecho procesal electoral mexicano, México, Editorial Porrúa, 2006.

Rivera Reynaldos, Lisette Griselda, Desamortización y nacionalización de bienes civiles y eclesiásticos en Morelia, 1856-1876, Morelia, umsnh, 1996.

Rosas, Salas, Sergio Francisco, “¿Libertad o conciencia o espíritu de partido? La polémica en torno al juramento civil de Clemente de Jesús Munguía, 1851”, en Ulúa, 22, 2013, pp. 71-101.

Sordo Cedeño, Reynaldo, "El Congreso y la formación del EstadoNación en México, 1821-1855", en Josefina Vázquez (coordinadora), La fundación del Estado mexicano, Nueva Imagen, México, 1997.

Tamayo, Jorge (selección y notas), Benito Juárez. Documentos, discursos y correspondencia, México, Editorial Libros de México, 1972.

Villegas Revueltas, Silvestre, "Santannismo, reforma liberal y las campañas de Puebla en 1856", en Estudios de historia moderna y contemporánea de México, núm. 40, julio-diciembre 2010, pp. 13-52. 